\title{
Third study on WHO MPOWER Tobacco Control Scores in Eastern Mediterranean countries 2011-2015
}

\author{
Gholamreza Heydari ${ }^{1}$, Arezoo EbnAhmady ${ }^{2}$, , Harry A. Lando ${ }^{3}$, Fahimeh Chamyani ${ }^{4}$, Mohammadreza Masjedi ${ }^{5}$,
} Mohammad B. Shadmehr ${ }^{6}$ and Lida Fadaizadeh ${ }^{7}$

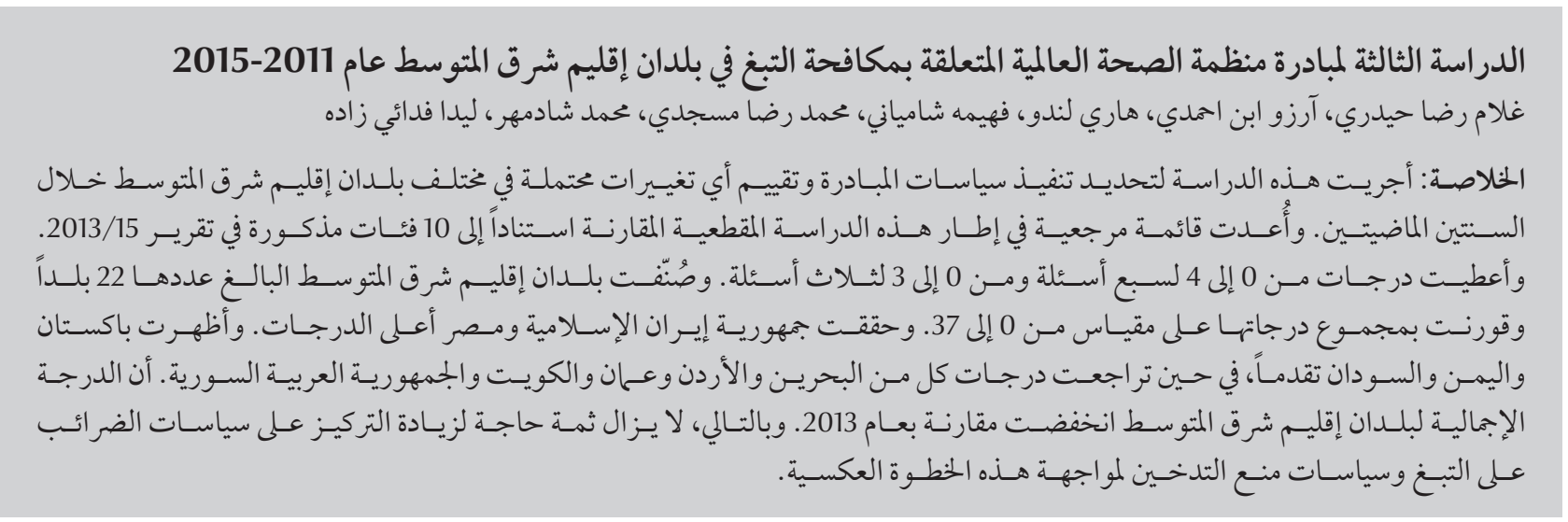

ABSTRACT This study was conducted to quantify the implementation of the MPOWER policies and to assess any possible changes across Eastern Mediterranean Region (EMR) countries. In this comparative cross-sectional study based on 10 categories mentioned in MPOWER report 2015 a checklist was designed. Seven questions were scored from 0-4 and three from 0-3. The 22 EMR countries were ranked and compared by their total score on a scale of 0-37. The highest scores were achieved by the IsImaic Republic of Iran and Egypt. Pakistan, Sudan and Yemen showed progress, while Bahrain, Jordan, Kuwait, Oman, and the Syrian Arab Republic had decreased scores. The total score of the EMR countries had decreased compared to 2013. Thus, there remains a need for greater focus on tobacco taxation and smoke-free policies to address this retrograde step.

Troisième étude sur les scores MPOWER OMS en matière de lutte antitabac dans les pays de la Région de la Méditerranée orientale durant la période 2011- 2015

RÉSUMÉ La présente étude a été conduite pour quantifier la mise en œuvre des politiques MPOWER et évaluer les changements éventuellement survenus dans les pays de la Région de la Méditerranée orientale entre 2013 et 2015. Dans la présente étude transversale comparative basée sur 10 catégories mentionnées dans le rapport MPOWER de l'année 2015, une liste de contrôle a été mise au point. Sept questions ont été notées sur une échelle de 0 à 4 et trois questions sur une échelle de 0 à 3. Les 22 pays de la Région de la Méditerranée orientale ont été classés et comparés selon leurs scores totaux sur une échelle de 0 à 37. Les scores les plus élevés ont été obtenus par la République islamique d'Iran et l'Égypte. Le Pakistan, le Soudan et le Yémen ont montré des progrès, alors que Bahreïn, la Jordanie, le Koweït, Oman et la République arabe syrienne ont obtenu des scores inférieurs par rapport aux études précédentes. Les scores totaux des pays de la Région de la Méditerranée orientale ont baissé par rapport à l'étude de 2013. Il est donc nécessaire d'accorder une plus grande importance aux taxes sur le tabac et aux politiques sans tabac pour faire face à cette régression.

'Tobacco Prevention and Control Research Center, National Research Institute of Tuberculosis and Lung Diseases, Shahid Beheshti University of Medical Sciences, Tehran, Islamic Republic of Iran. ${ }^{2}$ School of Dentistry, Shahid Beheshti University of Medical Sciences, Tehran, Islamic Republic of Iran (Correspondence to: A. EbnAhmady: a.ebne@yahoo.com). ${ }^{3}$ School of Public Health Directory, University of Minnesota, United States of America. ${ }^{4}$ Department of Library, National Research Institute of Tuberculosis and Lung Diseases, Shahid Beheshti University of Medical Sciences, Tehran, Islamic Republic of Iran. ${ }^{5}$ Chronic Respiratory Research Center, National Research Institute of Tuberculosis and Lung Diseases, Shahid Beheshti University of Medical Sciences, Tehran, Islamic Republic of Iran. ${ }^{6}$ Tracheal Disease Research Center, National Research Institute of Tuberculosis and Lung Diseases, Shahid Beheshti University of Medical Sciences, Tehran, Islamic Republic of Iran. ${ }^{7}$ Telemedicine Research Center, National Research Institute of Tuberculosis and Lung Diseases, Shahid Beheshti University of Medical Sciences, Tehran, Islamic Republic of Iran. Received: 09/06/15; accepted: 16/01/17 


\section{Introduction}

Since 1980, large reductions in the estimated prevalence of daily smoking have been observed globally for both men and women. However, due to population growth, the number of smokers has increased significantly despite these reductions. Although trend analysis has revealed that several industrialized countries have achieved large reductions in the prevalence of smoking, in other countries the number of smokers is increasing and intensified tobacco control efforts are urgently needed (1). Total tobacco-attributable deaths are projected to rise from 5.4 million in 2005 to 6.4 million in 2015 and 8.3 million in 2030 and tobacco will continue to be the single largest preventable cause of death (2).

In the World Health Organization (WHO) Eastern Mediterranean Region, where smoking rates are high among men and are projected to grow, there is a need for a comprehensive tobacco control programme $(3,4)$. However, a major barrier to implementation of such a programme is the tobacco industry, which has used huge profits to expand its production, distribution and sale of tobacco products (4). WHO has developed the Framework Convention on Tobacco Control to provide new legal dimensions for international health cooperation in combating the global tobacco epidemic (5). WHO has introduced a package of measures under the acronym MPOWER with the aim of reducing tobacco consumption and prevalence. This package focuses on 6 proven measures: Monitoring tobacco use and prevention policies; Protecting people from tobacco smoke; Offering help to quit tobacco use; Warning about the dangers of tobacco; Enforcing bans on tobacco advertising, promotion and sponsorship; and Raising taxes on tobacco (6). Global experience has demonstrated that implementation of these measures provides a favourable environment for reduction in tobacco consumption and its health effects (7-9).

WHO has published 3 MPOWER reports in 2011,2013 and 2015 on the activities of the Eastern Mediterranean countries in relation to these 6 policies (10). We subsequently undertook 2 studies based on the 2011 and 2013 WHO MPOWER reports. We rated the 6 recommended programmes in the Islamic Republic of Iran and Egypt, which were the 2 countries with the highest scores, indicating that these countries had acceptable tobacco control programmes $(11,12)$. In the current study, we assessed and compared changes in tobacco control scores with the same methods used in the 2011, 2013 and 2015 WHO reports.

\section{Methods}

This was a comparative cross-sectional study of data from the WHO programme of tobacco prevention in the Eastern Mediterranean Region (MPOWER 2011, 2013 and 2015 reports) $(12,13)$. We used the same checklist as in the previous 2 studies. The checklist was designed previously by Iranian and international tobacco control specialists and its cutoffs were set according to the scoring of key sections of the MPOWER 2011,2013 and 2015 reports. The checklist contained 7 questions with 5 options ranging from a minimum score of 0 to a maximum of 4 , and 3 questions ranging from a minimum score of 0 to a maximum of 3 , resulting in a maximum possible score of 37. Each point for which data were not available was scored as 0 . Consistent with the 2 previous studies, 2 trained raters administered the assessment (an intraclass correlation coefficient of 0.8 was calculated between these 2 raters). Data entry was done by the 1 st rater independently and was checked by the 2 nd rater. The principal investigator (GH) randomly selected 2 or 3 of the entered data to monitor their ratings.
The scores were summed and the rankings calculated. The checklist, together with its scoring and scale, is shown in Table 1.

\section{Results}

Countries were ranked by scores obtained for each indicator for each activity, and the total scores are shown in Table 2. The highest total scores were achieved by the Islamic Republic of Iran, Egypt, and Pakistan. Despite its overall high score, the Islamic Republic of Iran did not score high on smoke-free compliance and tobacco taxation. Thirteen countries did not report adult daily smoking prevalence. The indicators with the highest and lowest combined score for all countries were advertising bans and smoke-free policy compliance (67 and 18, respectively).

Table 3 shows changes in the MPOWER scores among Eastern Mediterranean countries over a 5-year period based on the 2011, 2013 and 2015 WHO reports on tobacco control. Thirteen countries achieved more than half of the maximum score $(\geq 19)$. However, only 7 countries showed improvement in their overall tobacco control programmes and a decrease in total points for all countries was seen in 2015 when compared to 2013. Saudi Arabia and Morocco received the same scores in 2013 and 2015. The largest improvements in total scores from the 2013 report were for Pakistan (increase of 6) and Yemen (increase of 5). Surprisingly, we noted a decrease in scores for adult daily smoking prevalence scores, from 44 in 2011 (11) to 25 in 2015; advertising ban compliance, from 55 in 2013 (12) to 31 in 2015; and smoke-free policy compliance, from 30 in 2013 (12) to 18 in 2015 (Table 2). For monitoring and taxation score we had no changes and for other MPOWER measures we had a slight increase in scores. 


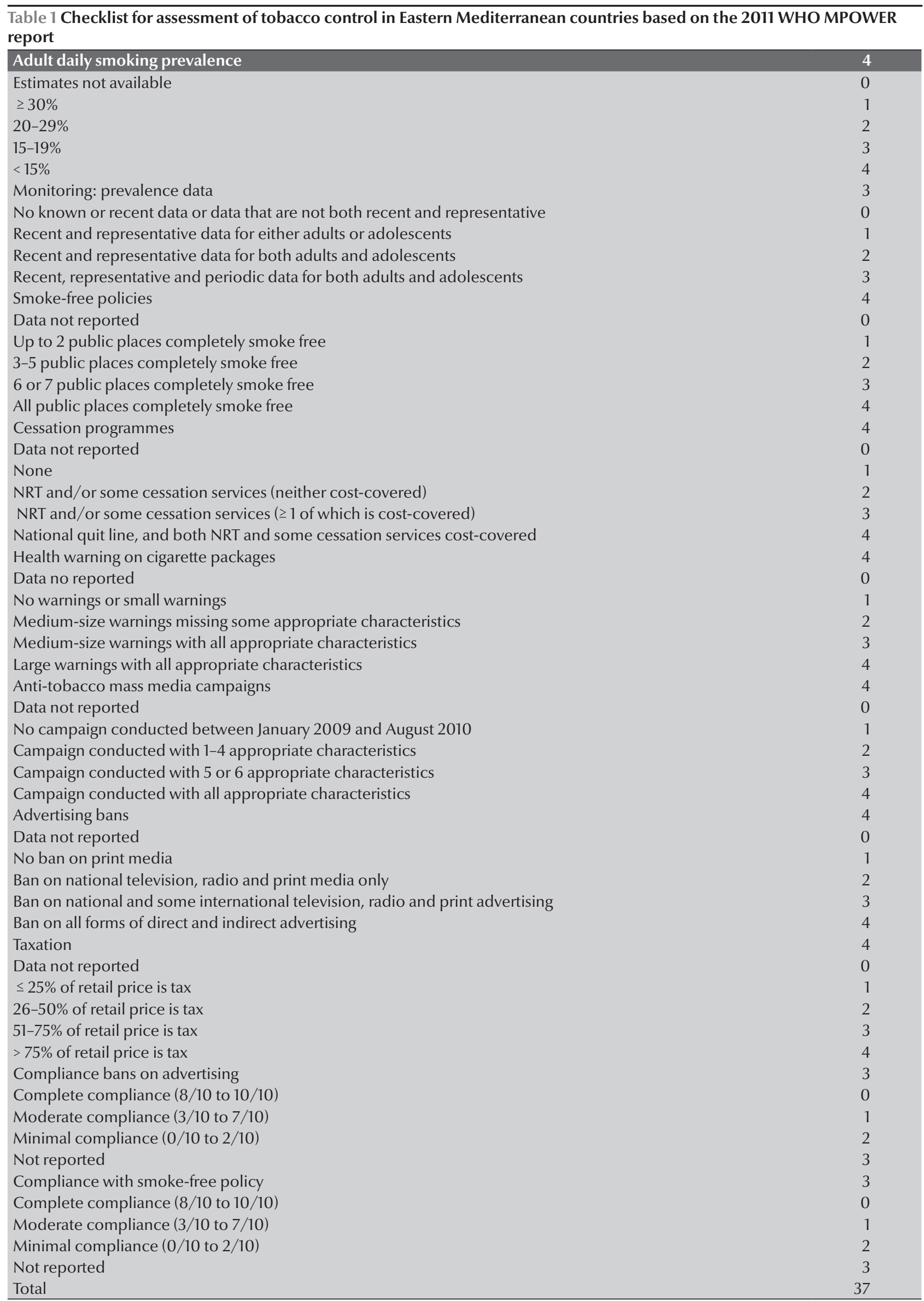

$N R T=$ nicotine replacement therapy 


\begin{tabular}{|c|c|c|c|c|c|c|c|c|c|c|c|}
\hline Country & 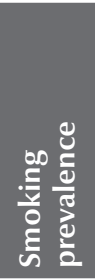 & 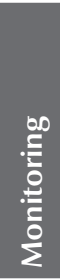 & 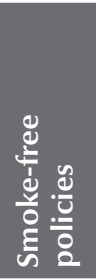 & 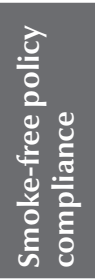 & 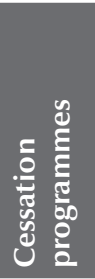 & 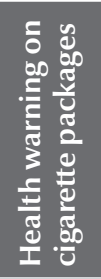 & 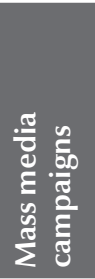 & 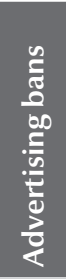 & 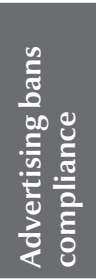 & 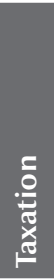 & $\begin{array}{c}\text { Total } \\
\text { scores } \\
2015\end{array}$ \\
\hline Islamic Republic of Iran & 4 & 3 & 4 & 2 & 4 & 4 & 4 & 4 & 3 & 1 & 33 \\
\hline Egypt & 2 & 3 & 2 & 2 & 3 & 4 & 3 & 4 & 2 & 4 & 29 \\
\hline Pakistan & 3 & 3 & 4 & 1 & 3 & 3 & 3 & 3 & 1 & 3 & 27 \\
\hline Lebanon & 2 & 2 & 4 & 1 & 3 & 2 & 4 & 3 & 1 & 2 & 24 \\
\hline Kuwait & 0 & 3 & 3 & 1 & 4 & 3 & 3 & 3 & 1 & 2 & 23 \\
\hline Saudi Arabia & 4 & 2 & 4 & 3 & 3 & 3 & 1 & 1 & 1 & 1 & 23 \\
\hline Libya & 0 & 2 & 4 & 1 & 3 & 1 & 4 & 4 & 3 & 1 & 23 \\
\hline Yemen & 0 & 2 & 3 & 1 & 2 & 3 & 2 & 4 & 2 & 3 & 22 \\
\hline West bank and Gaza Strip & 0 & 3 & 4 & 1 & 2 & 1 & 2 & 3 & 1 & 4 & 21 \\
\hline Morocco & 3 & 1 & 2 & 2 & 2 & 1 & 1 & 3 & 3 & 3 & 21 \\
\hline Tunisia & 0 & 1 & 1 & 0 & 3 & 1 & 4 & 3 & 4 & 3 & 20 \\
\hline Djibouti & 0 & 2 & 3 & 0 & 2 & 4 & 3 & 4 & 0 & 2 & 20 \\
\hline Jordan & 1 & 1 & 2 & 1 & 3 & 2 & 1 & 3 & 1 & 4 & 19 \\
\hline Qatar & 0 & 3 & 1 & 0 & 3 & 3 & 1 & 3 & 3 & 1 & 18 \\
\hline United Arab Emirates & 0 & 1 & 0 & 0 & 4 & 3 & 3 & 4 & 0 & 1 & 16 \\
\hline Sudan & 0 & 1 & 1 & 0 & 1 & 1 & 3 & 3 & 3 & 3 & 16 \\
\hline Bahrain & 2 & 0 & 0 & 0 & 3 & 3 & 1 & 4 & 0 & 2 & 15 \\
\hline Oman & 4 & 1 & 1 & 0 & 3 & 3 & 1 & 1 & 0 & 1 & 15 \\
\hline Iraq & 0 & 1 & 2 & 1 & 3 & 2 & 1 & 3 & 1 & 1 & 15 \\
\hline Syrian Arab Republic & 0 & 1 & 3 & 0 & 3 & 1 & 1 & 3 & 0 & 0 & 12 \\
\hline Afghanistan & 0 & 0 & 2 & 1 & 2 & 1 & 1 & 3 & 1 & 1 & 12 \\
\hline Somalia & 0 & 0 & 1 & 0 & 1 & 1 & 0 & 1 & 0 & 0 & 4 \\
\hline Total & 25 & 36 & 51 & 18 & 60 & 50 & 47 & 67 & 31 & 43 & 428 \\
\hline
\end{tabular}

\section{Discussion}

The study found that during 5 years of implementation of the MPOWER package in Eastern Mediterranean countries, tobacco control programmes in the Islamic Republic of Iran and Egypt continued to compare favourably with those of other countries in the region. Although several countries such as Pakistan, Libya, Yemen, Qatar and Sudan improved their scores, many others, Lebanon, Kuwait, West Bank and Gaza Strip, Tunisia, Djibouti, Jordan, United Arab Emirates, Bahrain, Oman, Iraq, Syrian Arab Republic, Afghanistan and Somalia, saw a reduction in their scores. More recent tobacco control programmes have attempted to decrease smoking rate (by using MPOWER measures), but they might need more time to be effective in Eastern Mediterranean countries. Our previous 2 studies $(11,12)$ used the same methodology that was used for the MPOWER report in 2015. Our 3 studies demonstrate that countries in the region need to take steps to achieve improvements in tobacco control.

It is important that the countries concerned carefully examine their scores, especially those that had reduced scores, in order to have greater focus on implementation of MPOWER policies and improving areas of weakness. In 2006, Joossens and Raw (13) compared tobacco control scores in European countries through a checklist. We used the same method to compare 22 Eastern Mediterranean countries, among which the Islamic Republic of Iran, Jordan and Egypt received the highest scores (14). Our previous 2 studies $(11,12)$ compared tobacco control programmes among Eastern Mediterranean countries based on the WHO MPOWER reports published in 2011 and 2013. By using a coherent and similar checklist and a hand-scoring system among the studies, we were provided an opportunity to monitor trends in 


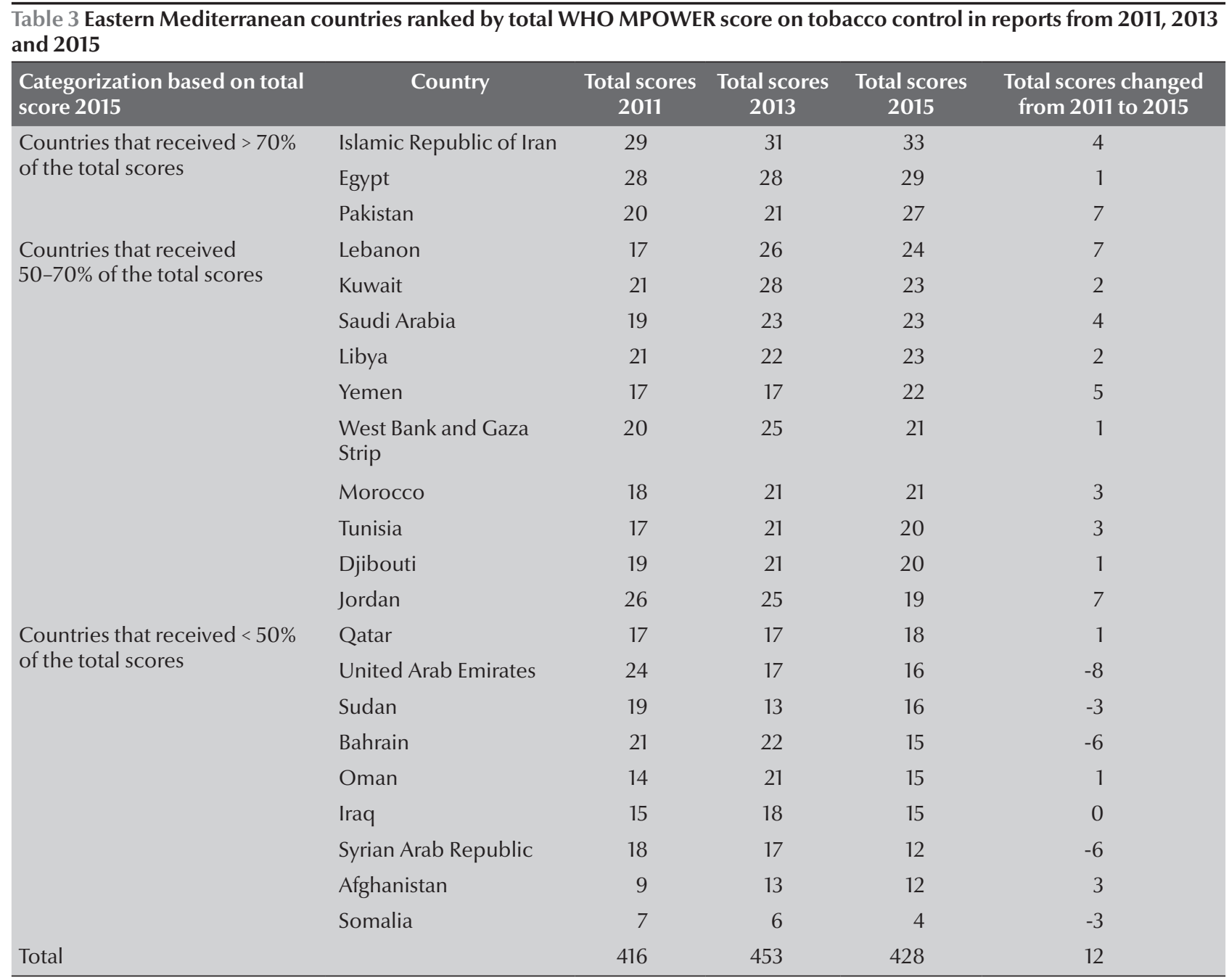

increases and decreases in tobacco control indicators. In comparing the total scores of countries in the Eastern Mediterranean Region in 2011, 2013 and 2015 we found a decline of 25 points in 2015 compared to 2013 in contrast to the 37 -point increase in 2013 compared to 2011 . Of particular importance is the fact that tobacco taxation programmes often have been unsuccessful even in countries with high overall scores, such as the Islamic Republic of Iran (10 of 22 Eastern Mediterranean countries were unsuccessful in implementing a tobacco taxation programme during the past 5 years). The Islamic Republic of Iran needs more emphasis on improving its tobacco taxation programme, while Egypt, which also scored high overall, needs more concentration on smokefree polices.
Our study had some limitations. We used data from the $2015 \mathrm{WHO}$ MPOWER report, which were not surveillance data. It is important to use surveillance data for more critical analysis, but such data are not available for all Eastern Mediterranean countries. Also, the MPOWER report did not refer to water pipe and another forms of tobacco smoking; political, social and economic environmental issues that are supportive or act as barriers to tobacco control; industry interference; and other particular polices that would be likely to reduce smoking prevalence (15). These factors could be investigated in future studies.

In conclusion, based on a comparison of MPOWER reports published in 2013 and 2015, tobacco control programmes have improved in the Islamic Republic of Iran, Egypt and Pakistan. However, the overall situation in the Eastern Mediterranean countries is still far from ideal and the total score actually declined between 2013 and 2015 . More emphasis is especially needed on smoke-free and taxation policies in this region.

\section{Acknowledgements}

We gratefully acknowledge the generous assistance and valuable editing provided to us by Barbara M. Lux, from Minnesota University, USA

Funding: None.

Competing interests: None declared. 


\section{References}

1. Ng M, Freeman MK, Fleming TD, Robinson M, Dwyer-Lindgren $\mathrm{L}$, Thomson B et al. Smoking prevalence and cigarette consumption in 187 countries, 1980-2012. JAMA. 2014 Jan 8;311(2):183-92. PMID: 24399557

2. Mathers CD, Loncar D. Projections of global mortality and burden of disease from 2002 to 2030. PLoS Med. 2006 Nov;3(11):e442. PMID: 17132052

3. Levine R, Kinder M. Millions saved: proven success in global health. Washington (DC): Routledge; 2006.

4. Battling big tobacco: Mike Wallace talks to the highest-ranking tobacco whistleblower. CBS News, 2005 (http://www.cbsnews.com/news/battling-big-tobacco/, accessed 30 May 2017).

5. WHO Framework Convention on Tobacco Control. Geneva: World Health Organization; 2003 (http://www.who.int/fctc/ text_download/en/, accessed 15 May 2017).

6. WHO Report on the global tobacco epidemic, 2008: the MPOWER package. Geneva: World Health Organization; 2008 (http://apps.who.int/iris/bitstre am/10665/43818/1/9789241596282_eng.pdf, accessed 15 May 2017).

7. Guindon GE, Boisclair D. Past, current and future trends in tobacco use. Washington DC: World Bank; 2003 (http://documents.worldbank.org/curated/en/374771468128405516/pd f/292650Guindon1Past10current10whole.pdf, accessed 15 May 2017).

8. Basu S. Glantz S, Bitoon A, Millet C. The effect of tobacco control measures during a period of rising cardiovascular disease risk in India: a mathematical model of myocardial infarction and stroke. PloS Med. 2013;10(7):e1001480. PMID:23874160
9. Levy D, Ellis JA, Mays D, Huang A-T. Smoking related deaths averted due to three years of policy progress. Bull World Health Organ. 2013 Jul 1;91(7):509-18. PMID:23825878

10. WHO report on the global tobacco epidemic, 2015. Raising taxes on tobacco (http://www.who.int/tobacco/global_report/2015/en/, accessed 15 May 2017).

11. Heydari G, Talischi F, Algouhmani H, Lando HA, Ahmady AE. WHO MPOWER tobacco control scores in the Eastern Mediterranean countries based on the 2011 report. East Mediterr Health J. 2013 Apr;19(4):314-9. PMID:23882955

12. Heydari G, Ebn Ahmady A, Lando HA, Shadmehr MB, Fadaizadeh L. The second study on WHO MPOWER tobacco control scores in the Eastern Mediterranean Countries based on the 2013 report: improvements over two years. Arch Iran Med. 2014 Sep;17(9):621-5. PMID:25204478

13. Joossens L, Raw M. The Tobacco Control Scale: a new scale to measure country activity. Tob Control. 2006 Jun;15(3):247-53. PMID:16728757

14. Heydari G, Talischi F, Masjedi MR, Alguomani $\mathrm{H}$, Joossens L, Ghafari M. Comparison of tobacco control Policies in the Eastern Mediterranean countries based on tobacco control scale score. East Mediterr Health J. 2012 Aug;18(8):804-10. PMID:23057368

15. Levy DT, Fouad H, Levy J, Dragomir A, El Awa F, Application of the Abridged SimSmoke Model to four Eastern Mediterranean countries. Tob Control, 2016 Jul;25(4):413-21. PMID:26080365. 